\title{
ESPELHOS QUEBRADOS: imagem de uma docência auto empreendedora
}

\author{
Dulce Mari da Silva Voss \\ Universidade Federal do Pampa - UNIPAMPA, Brasil
}

\begin{abstract}
Resumo
Devido as medidas tomadas pelas instâncias administrativas do Estado Brasileiro para contenção da pandemia do COVID-19, as escolas públicas foram fechadas e a adoção do ensino remoto serviu de justificativa para o cumprimento do ano letivo, em 2020. Um mercado educacional está em franca expansão no contexto pandêmico e requer a aquisição de competências e habilidades no manuseio de dispositivos tecnológicos digitais e virtuais. Analisar os efeitos do ensino remoto no trabalho pedagógico norteou a realização de um Estudo de Caso que envolveu professoras da cidade de Bagé (RS) e municípios vizinhos. Considera-se que as práticas discursivas e não discursivas engendradas nas falas das professoras engendram tecnologias de governo da conduta docente. Efeito da ordem biopolítica neoliberal que afeta a educação nos tempos presentes. Projeta-se, assim, uma imagem de docência espelhada no empreendedorismo empresarial. Performatividade narcisista que requer a responsabilização moral de sujeitos docentes comprometidos com a eficácia da nova modalidade de ensino.
\end{abstract}

Palavras-chave: Biopolítica; Neoliberalismo; Docência; Auto empreendedorismo.

\begin{abstract}
Due to the measures taken by the administrative bodies of the Brazilian State to contain the COVID19 pandemic, public schools were closed and the adoption of remote education served as a justification for the fulfillment of the school year in 2020. An educational market is booming in the pandemic context and requires the acquisition of skills and skills in the handling of digital and virtual technological devices. Analyzing the effects of remote education on pedagogical work led to a Case Study involving teachers from the city of Bagé (RS) and neighboring municipalities. It is considered that the discursive and non-discursive practices engendered in the teachers' speeches engender technologies of government of the teaching conduct. Effect of the neoliberal biopolitical order that affects education in the present times. Thus, an image of teaching is projected in entrepreneurial entrepreneurship. Narcissistic performivity that requires the moral accountability of teaching subjects committed to the effectiveness of the new teaching modality.
\end{abstract}

Keywords: Biopolitics; Neoliberalism; Teaching; Self entrepreneurship.

ISSN 1645-1384 (online) www.curriculosemfronteiras.org 
Quando eu te encarei frente a frente não vi o meu rosto Chamei de mau gosto o que vi, de mau gosto, mau gosto

É que Narciso acha feio o que não é espelho

E à mente apavora o que ainda não é mesmo velho Nada do que não era antes quando não somos mutantes.

Caetano Veloso

\section{Frente ao espelho}

As escolas e as universidades estão vazias e silenciosas. Para onde foram os fluxos que moviam a vida e o trabalho docente? Foram distribuídos, isolados, canalizados, instrumentalizados por uma "nova ordem"? Ou pela ordenação do mesmo? Que estranha docência é essa projetada nas telas-espelho? Se desconhece o que nela se mostra? Desejarse-á essa "imagem narcísica" ${ }^{1}$ " fabricada pelas grandes máquinas acopladas aos corpos? Como pensar o trabalho docente em tempos de COVID-19²?

$\mathrm{O}$ isolamento social, medida sanitária tomada pelas instâncias administrativas do Estado brasileiro para contenção da pandemia, afetou diretamente a vida das escolas e das comunidades escolares. Na cidade de Bagé (RS), a Secretária Municipal de Educação (SMED) determinou a suspensão das atividades presenciais nas escolas públicas em 19 de março de 2020. Professores/as foram requisitados/as a executar as aulas com recursos próprios nos espaços privados dos seus domicílios. As aulas gravadas foram, inicialmente, transmitidas pelo canal do youtube da TV Câmara (canal de televisão do poder legislativo municipal). Porém, diante da ineficácia do esquema montado, uma vez que a maioria dos estudantes não dispunha de condições materiais para acessar as atividades pedagógicas via internet, os/as professores/as começaram a postar os conteúdos e as tarefas em grupos criados no whatzapp, o que também não funcionou muito bem. Para sanar as dificuldades, professores/as passaram a fazer plantão nas escolas e atender os familiares dos/as estudantes que lá buscavam as atividades relativas ao ano letivo. Mas, os resultados foram efêmeros. Muitos estudantes das escolas das periferias da cidade precisaram procurar trabalho no mercado informal para ajudar no sustento de suas famílias e não puderam cumprir as tarefas escolares. Revelou-se, assim, o aprofundamento da exclusão social associada à exclusão digital na pandemia, crescimento do desemprego, da pobreza e falta de políticas públicas efetivas de atendimento às necessidades básicas da população bajeense.

Essas circunstâncias instigaram a realização de um Estudo de Caso que envolveu professoras das escolas públicas municipais da cidade de Bagé e municípios vizinhos empenhadas em dar conta do ensino remoto. Com base nas narrativas das professoras procurou-se analisar os efeitos gerados no trabalho pedagógico e na conduta docente frente às novas demandas.

A análise das narrativas seguiu a perspectiva foucaultiana, atentando para as práticas discursivas e não discursivas engendradas nos discursos das professoras. De acordo com Foucault (2005) o discurso produz os objetos e sujeitos de que fala. Contudo, o discurso não se resume a um fenômeno de mera expressão de algo. Não se trata de tomar as formações 
discursivas como representações das coisas ditas e manifestadas graças a uma pretensa consciência. Objetos discursivos se materializam no e pelo próprio discurso, no momento mesmo em que é produzido e põe em funcionamento certa vontade de verdade. Nada há de encoberto no discurso. Discursos colocam em ação práticas discursivas (o dito, o anunciado) e não-discursivas (o não-dito, ou seja, relações de poder-saber e modos de subjetivação) que visam fabricar certa vontade de verdade.

É preciso colocar em ação o dito e o não-dito. Segundo Fischer (2001), trabalhar duramente com o próprio discurso e deixá-lo emergir em sua complexidade. A investigação arquegenealógica opera a análise discursiva no sentido de indagar: como determinado discurso, em certo momento histórico, torna-se verdadeiro? Que relações de poder-saber permitem ao discurso tornar-se verdadeiro? Como age no governo de si e dos outros? Como nos tornamos sujeitos de um certo tipo por meio do discurso? Busca-se, assim, a vontade de verdade construída e agenciada discursivamente.

Questões que nortearam o estudo feito. Nele, analisa-se a vontade de verdade colocada em ação pelas práticas discursivas e não-discursivas das professoras entrevistadas frente à demanda do trabalho remoto na pandemia. Percebe-se que tal produção engendra o governo da conduta docente, capturando e efetuando uma subjetividade atrelada à lógica empreendedora e utilitarista da aquisição de competências e habilidades de uso das tecnologias digitais, à mercê das contingências sociais, pedagógicas e humanas daí decorrentes. Com isso, a expansão do mercado de insumos, programas e outros produtos tecnológicos se intensifica em relação ao trabalho pedagógico. Incremento das políticas privatistas na educação, em curso há bastante tempo no Brasil.

Políticas de regulação da educação e da docência que visam capturar e posicionar, hierarquicamente, condutas auto empreendedoras sustentadas pela moral de responsabilização individual em todos os campos de ação humana, profissional e social, na contemporaneidade. Exercício de governo e autogoverno da docência que reflete, como num espelho, a imagem de sujeito auto empreendedor, disposto, bem-sucedido na ótica neoliberal.

Regulação que pretende fazer da educação um serviço e, consequentemente, do profissional docente um prestador desse serviço, um ávido consumidor e manipulador de tecnologias digitais da comunicação e da informação. Docente que informa, dá forma a si, ao desejar ajustar sua conduta à imagem empreendedora não apenas em relação a si mesmo, mas também aos estudantes e familiares.

As professoras que participaram da pesquisa anunciam o desejo de cumprir com as demandas trazidas pelo ensino remoto. Afirmaram terem se esforçado ao máximo para aprenderem e criarem maneiras de incorporar as novas tecnologias no seu trabalho cotidiano. Manifestaram uma certa naturalização quanto à educação à distância, considerando ser essa uma tendência irreversível a exigir a atualização do trabalho docente. Algumas delas, porém, levantaram questionamentos sobre as condições de viabilização da metodologia, as limitações geradas em termos pedagógicos e a falta de acesso aos dispositivos tecnológicos por parte das escolas, dos estudantes e dos familiares situados em contextos de exclusão social. Também apontaram a falta de orientações necessárias em relação ao ensino remoto. Houve ainda uma delas que afirmou a necessidade de uma mudança profunda e positiva nas relações 
pedagógicas entre docentes e discentes, por entender que se trata de romper com o ensino tradicional baseado na transmissão do conhecimento pelo/a professor/a e na recepção passiva dos/as estudantes.

Considera-se, portanto, que, no contexto analisado, a demanda do ensino remoto produziu uma imagem narcísica da docência, pelo modo como as professoras declararam assumir a responsabilização individual de eficácia dos resultados em relação ao cumprimento do ano letivo. Com isso, não se está negando o uso das novas tecnologias como ferramentas que podem incrementar o trabalho pedagógico. A questão vai além disso. Trata-se de problematizar as contingências sob as quais acontece a produção da docência enquanto efeito das biopolíticas neoliberais.

Nesse sentido, o que parece mudar são os meios e não os fins. Até porque, ao que tudo indica, o uso das tecnologias digitais no ensino remoto não repercutiu na transformação da mera transmissão de conteúdos e atribuição de notas às atividades repassadas aos/as estudantes. Desse modo, manteve-se a repetição mecânica dos conhecimentos, reforçando a concepção produtivista e meritocrática da educação, aliada ao padrão social, econômico e cultural capitalista.

Como adverte Rolnik (2018), no atual modelo capitalístico, não é apenas a energia física que é explorada, mas o próprio desejo, ou seja, uma captura do inconsciente vital que se torna possível, das forças que movemos para dar sentido a nossa própria vida e ao que fazemos de nós e dos outros com os quais nos relacionamos.

Tensionar a produção imagética narcísica, ensaiar um possível "atravessamento do espelho", ou seja, esboçar uma proposta de desmontagem dessa lógica que permite a máquina neoliberal global funcionar e efetuar a captura do desejo e a fabricação de condutas docentes, auto empreendedoras, é o proposito deste texto.

\section{Tempos narcísicos}

De tempos em tempos, surge o discurso da crise como causa que justifica todo o resto. Todavia, não se trata desta ou daquela crise esporádica, e sim da produção de uma realidade a ser operada com base numa discursividade permanente de crise, para que a perversidade do capitalismo e a versão correlata do Estado neoliberal se consolidem como padrão de existência, sociabilidade e ação humana.

Gerenciamento biopolítico da vida que privilegia os negócios financeiros e os lucros empresariais. Segundo Foucault (2008), o biopoder refere-se ao poder que se aplica à vida dos indivíduos enquanto seres que pertencem a espécie humana. Deixar viver ou morrer é o modo como o biopoder funciona no governo das populações. Para isso, cada indivíduo deve assumir e empreender esforços para moldar a própria conduta aos apelos da máquina estatal neoliberal e do desenvolvimento econômico capitalista.

$\mathrm{Na}$ contemporaneidade, a aliança entre o capital financeirizado e os Estados neoliberais têm engendrado a regulação/intervenção da vida planetária como um todo, de modo a submeter as populações ao jogo de interesses do capital concorrencial, uma vez que: 
As grandes potências industriais e financeiras produzem, desse modo, não apenas mercadorias, mas também subjetividades. Produzem subjetividades agenciadas dentro do contexto biopolítico: produzem necessidades, relações sociais, corpos e mentes - ou seja, produzem produtores. Na esfera biopolítica, a vida é levada a trabalhar para a produção e a produção é levada a trabalhar para a vida. É uma grande colmeia na qual a abelha rainha supervisiona continuamente produção e reprodução (Hardt; Negri, 2012, p. 51).

É nesse quadro global de gestão biopolítica que a pandemia do COVID-19 não abalou o regime de governamentalidade neoliberal e os interesses capitalistas, pelo contrário, tornouos ainda mais evidentes, já que o agravamento da situação de adoecimento e morte demandou das populações e dos indivíduos estratégias de operacionalização dos riscos. No caso brasileiro, o número exorbitante de óbitos ${ }^{3}$ foi agravado pela debilidade das políticas públicas sanitárias, em termos não só de contenção da pandemia, mas de acesso à saúde como direito individual e social. Com isso, o Estado neoliberal tem agido para "ampliar ao máximo o livre fluxo de capital transnacional, já instalado no país a várias décadas" (Rolnik, 2018, p. 100).

Em relação às políticas educacionais, o modelo neoliberal tem sido incorporado via privatização, antes mesmo da pandemia. A educação perde cada vez mais o sentido de direito a ser provido e garantido via políticas públicas estatais e adquire o caráter de serviço disponibilizado no mercado.

A governamentalidade neoliberal tem gerado efeitos perversos na educação pública brasileira e no exercício da profissão docente, como a redução no contingente de professores/as que ingressam na carreira por meio de concursos públicos, o que permite a contratação de mão-de-obra temporária no magistério, a sobrecarga e precarização das condições de trabalho e o controle das ações pedagógicas via monitoramento tecnológico dos desempenhos. Práticas de governo voltadas à qualidade empresarial e a produtividade meritocrática.

Voss (2021) problematiza as políticas educacionais contemporâneas fundamentadas na qualidade empresarial da educação, as quais são gerenciadas por meio da avaliação de resultados nos desempenhos dos alunos nos exames nacionais, atribuídos às escolas e redes de ensino. Políticas educacionais entendidas como:

[...] fabricações de discursos e ações agenciadas num jogo de forças e influências de múltiplas demandas, provenientes de órgãos dos governos nacionais e estaduais, de agências internacionais, de organizações sociais, de setores como o empresariado, partidos políticos, movimentos sociais, entre outros. Essas forças entram em conflito e geram agendas que legitimam algumas vozes em detrimento de outras. Desse modo, as políticas acontecem por meio de produções de discursos e ações que organizam a educação, constituem territórios, mas estão sempre sujeitas a mudanças, uma vez que há intensos movimentos de acomodação, resistência, agenciamentos que se efetivam de diferentes modos nos múltiplos contextos (Voss, 2021, p. 359). 
Políticas educacionais emanadas do Estado Brasileiro efetivadas também através da padronização dos currículos para o alcance das metas em termos de resultados e do nivelamento do ensino fragmentado em áreas de conhecimento e instrumentalizado em competências e habilidades.

Regulação da educação que na pandemia forçou o fechamento das escolas e universidades públicas e a adoção do ensino remoto atrelado ao uso de artefatos midiáticos, digitais, interativos, o que favoreceu a expansão empresarial, o mundo dos negócios e os lucros no campo da educação, à medida que investimentos materiais e de esforços psicológicos, pedagógicos e operacionais ficaram a cargo dos profissionais, das comunidades e dos estudantes, para que o ano letivo de 2020 fosse cumprido.

Tecnologias de governo das condutas que subjetivam professores/as, famílias e estudantes como empreendedores de si mesmo e responsáveis pelos seus êxitos ou fracassos. Subjetividades objetivadas em performances e dados quantificáveis, passíveis de serem medidas e classificadas. Como destaca Rose (1988) acerca dos procedimentos, métodos e técnicas que efetuam a produção de regimes de verdade:

Minha preocupação é com os novos regimes de verdade instalados pelo conhecimento da subjetividade, as novas formas de dizer coisas plausíveis sobre outros seres humanos e sobre nós mesmos, o novo licenciamento daqueles que podem falar a verdade e daqueles que estão sujeitos a ela, as novas formas de pensar o que pode ser feito a eles e a nós (Rose, 1988, p. 04).

Nos tempos pandêmicos, o governo da conduta docente tem sido guiado pelo neotecnicismo que cria demandas produtivistas e de consumo de bens e serviços. Grandes empresas e corporações transnacionais operam o mercado da cibercultura, da informática e de redes de informação e comunicação capturando desejos. Tais dispositivos exercem poder sobre interesses e estilos de condutas previsíveis, tornando os corpos empreendimentos de suas próprias ações. Racionalidade neoliberal que afeta populações e indivíduos por meio de técnicas de administração empresarial (Rosa; Puzio, 2013).

A preocupação de docentes em atender essas demandas é um indício de que:

Em primeiro lugar, as capacidades pessoais e subjetivas dos cidadãos têm sido incorporadas aos objetivos e aspirações dos poderes públicos. Isso não constitui apenas um nexo ao nível de uma abstrata especulação política. Constitui também um nexo ao nível de estratégias sociais e políticas e de instituições e técnicas de administração e regulação. Embora seja exagerado argumentar que aqueles que nos governam constroem agora suas ações totalmente ou em grande parte em termos das vidas interiores dos cidadãos, a subjetividade faz parte dos cálculos das forças políticas no que diz respeito ao estado da nação, às possibilidades e aos problemas enfrentados pelo país, às prioridades e às políticas. Os governos e os partidos de todos os matizes políticos têm formulado políticas, movimentado toda uma maquinaria, estabelecido burocracias e promovido iniciativas para regular a 
conduta dos cidadãos através de uma ação sobre suas capacidades e propensões mentais (Rose, 1988, p. 30-31).

Contudo, professores/as podem agir em aliança às políticas de captura dos seus corpos e desejos, sem questioná-las, assim como podem resistir a elas. Ao menos, suspeitar e pensar o que estão fazendo de si mesmo e dos outros diante dos ditames do mercado e da lógica neoliberal. Colocar sob suspeita os dispositivos engendrados nas/pelas práticas discursivas e não-discursivas que engendram o governo dos corpos e fabricação de sujeitos auto empreendedores é o tensionamento que move essa escrita. Pensar que, em meio às engrenagens de uma máquina de fabricação da docência capturada e seduzida pelas demandas criadas com o ajuste das políticas educacionais à ordem vigente, podem surgir poderes e saberes minoritários, atravessamentos, estratégias coletivas de retomada das decisões e dos fazeres docentes como criação singular.

\section{A imagem no espelho}

Nesse texto, a produção da imagem auto empreendedora da docência é entendida como efeito do governo das condutas docentes espelhadas nas demandas neoliberais e do mercado capitalista, as quais forçam o desempenho de competências e habilidades técnicas a serem operadas via ensino remoto nos ambientes isolados dos espaços domésticos.

A formulação desse argumento procede da análise feita das narrativas de dezoito professoras da cidade de Bagé (RS) e região vizinha que desempenharam o trabalho pedagógico por meio do ensino remoto, no ano de 2020, e que participaram de um Estudo de Caso.

Alguns dados coletados possibilitaram averiguar as condições sob as quais se deu o exercício da docência naquele contexto. Das dezoito professoras que participaram da pesquisa, duas atuavam em escolas particulares, as outras dezesseis trabalhavam em escolas públicas de Bagé. Cinco delas também atuavam em cidades vizinhas (uma em Dom Pedrito, três em Candiota e outra em Hulha Negra). Duas professoras jovens (27 anos de idade) eram iniciantes, pois, até 2020, tinham de um a cinco anos na docência. As demais, estavam na faixa etária dos 33 aos 54 anos de idade e já exerciam à docência de dez a vinte anos. Quanto à formação acadêmica, onze professoras contavam com a titulação de pós-graduação em nível de especialização, três tinham o mestrado e uma o doutorado e, outras três, as mais jovens, tinham apenas concluído a graduação.

Doze professoras, cuja idade correspondia a mais de trinta e cinco anos, cursaram a graduação em instituição privada. Isso porque, na época, não havia a oferta da educação superior pública nessa região. Pressupõem-se que elas contaram com um poder aquisitivo favorável para pagar seus estudos ou tiveram acesso ao crédito educativo do governo federal.

Além disso, é importante salientar que a maioria das professoras pós-graduadas obtiveram esse título em cursos de Educação à Distância (EAD) o que, em nosso país, tem sido uma política constante de formação docente que tem assumido um crescimento 
vertiginoso, tanto na graduação quanto na pós-graduação. Mais um indício da mercantilização da educação que repercute na precarização e aligeiramento da formação docente, em nome da redução de investimentos públicos provenientes do Estado.

Outros fatores relevantes para caracterização social das professoras referem-se ao estado civil e a condição de maternidade. Entre as dezoito que participaram da pesquisa, treze eram mães, sendo que, sete delas tinham de dois a quatro filhos, o que, provavelmente, exigia dessas mulheres a ocupação de um tempo diário para o exercício de tarefas domiciliares e de cuidado com as crianças, além do trabalho docente que, no contexto da pandemia, passou do espaço físico das escolas para o espaço privado dos lares. Professoras, cuja maioria (14) exercia a docência a mais de dez anos, sendo que, oito trabalharam virtualmente em mais de uma escola, mais de 20 horas/aula.

Sobre o trabalho docente e a ação pedagógica requerida no ensino remoto, as narrativas das professoras apontaram mais para uma mudança metodológica do que, necessariamente, para a transformação da concepção pedagógica acerca da transmissão de conhecimentos. A ideia de aquisição de habilidades e competências para dar conta do ensino remoto com o uso das ferramentas tecnológicas, sem que uma possível mudança no caráter e na relação pedagógica, tanto por parte das professoras quanto pelos estudantes, seja evidenciada, apareceu nas falas:

"É um método de ensino novo que estamos vivendo"; "Explicar a matéria sendo a aula à distância". (professora $\mathrm{A}$ )

"Não consegui explicar os conteúdos, pois sem internet as aulas pelo meet eram inviáveis". (professora E)

"Penso que é uma nova forma de ensinar e aprender". (professora G)

"No aspecto aprendizagem do professor ótimo nos levando a aprender as tecnologias". (professora B)

"O ensino a distância é um desafio diário na minha profissão, preciso estudar, aprender, testar e aplicar. Por vezes reinventar uma mesma aula mais de uma vez para que chegue o mais próximo possível do que se espera no presencial". (professora J)

"Todos tivemos que reaprender muita coisa"; "Penso também no que se entende por aprendizagem nesse momento"; "Acredito que tudo é uma formação de adaptação. Não vejo que seja negativo, desde que, estes possuam os recursos necessários e saibam utilizá-los". (professora K)

As professoras referiram-se à necessidade de procurar conteúdo nos livros impressos e em sites da internet. Enunciados que denotam a preocupação com uma adaptação metodológica alcançada pelo esforço individual e a responsabilidade moral com o êxito do ensino remoto, como percebido nos enunciados:

"O ensino à distância só será bem-feito a partir do momento que os alunos souberem ter autonomia de seus estudos. No ensino à distância o aluno tem que correr atrás. Estou fazendo o máximo para me adaptar e me reinventar". 
(professora A).

"Permite que o aluno desenvolva mais seu senso de responsabilidade e interesse pelas atividades". Embora tenha também afirmado que a aprendizagem dos estudantes tenha sido: "menos do que (ela) desejava". (professora C)

"Não é somente o professor que precisa se adaptar com o novo método de ensino, que abre sua casa, espaço e vida particular para receber seus alunos. É a sociedade, pais que precisam ter consciência dessa pandemia e, deixar de pensar que as escolas continuam fechadas porque professores não gostam de trabalhar. Não querem assumir o papel na educação dos seus filhos e confundem educação com ensino"; "Nosso aluno é tecnológico, mas para rede sociais, jogos etc. Não foram preparados para ensino à distância. Eles precisam do contato com seus colegas de sala, com à escola, professores e demais espaços da escola". (professora D) "Não considero que nosso esforço tenha sido recompensado com o aprendizado"; "Muitos pais não se comprometem com o ensino dos filhos e muitos não tem conhecimento suficiente para auxiliar nas atividades". (professora E)

"Estou fazendo a minha parte"; "Sempre pronta para ajudar"; "Os estudantes têm um ensino normal como teria nas escolas. A didática tá ali é só eles quererem"; "Acredito que quem quer estudar não vai ser afetado pelo modo que está recebendo a aprendizagem". (professora F)

"Daqui para frente vai ser assim e nós, professores e alunos, teremos que aceitar e nos qualificar"; "Para que haja um aprendizado real, nesse novo normal, os estudantes precisam querer aprender, precisam ter autonomia no aprendizado e essa habilidade eles ainda não desenvolveram" (professora G)

"Foi bom somente para aqueles que trabalharam de forma responsável durante o ano letivo". (professora $\mathrm{H}$ )

"(...) embora, os professores tenham realizado com esmero a produção de suas atividades escolares". (professora I)

"Aqueles que já tinham uma base bem-feita e que a família junto com a escola abraçou a causa". (professora $\mathrm{J}$ )

"O estranhamento foi geral, mas houve sim (aprendizagem)"; "Eu vejo com "bons" olhos, foi necessário a obrigatoriedade para que nos desafiássemos na investigação de jeitos, perspectivas diferentes de aula. Fui atingida totalmente, me desfiz em pedaços, mas me reinventei e não quero mais parar"; "Em suma, a educação a distância é vantajosa, mas, requer por parte do aluno mais disciplina, porém, ressalto a importância da interatividade entre os colegas, professores, equipe diretiva etc.". Essa professora também se referiu à responsabilidade de gestores/as: "Não é uma forma de ensino considerada inválida desde que seja uma modalidade melhor organizada pelos órgãos competentes que criam nossas políticas públicas educacionais". (professora K)

"Penso que para que a formação (dos estudantes) possa acontecer os perfis de aluno precisarão mudar. A espera pelo pensar exclusivo do professor não lhes cabe mais, terão que assumir outros papéis". (professora $\mathrm{M}$ )

As narrativas apontaram ainda que, o exercício da docência, durante a pandemia, demandou planejamento, transmissão das aulas, atendimento de um número expressivo de 
estudantes, correção de tarefas, avaliações, lançamento dos registros nas plataformas on-line, ou seja, elevada carga de trabalho a ser cumprida e, muitas vezes, com várias turmas e diferentes componentes curriculares.

Percebe-se que as professoras evidenciam o compromisso pessoal com a aquisição e utilização de um saber instrumental mediado pela capacidade de uso das tecnologias digitais e mídias. Daí porque, a produção discursiva da imagem da docência, em tempos pandêmicos, suscita o sentido de espelhamento no empreendedorismo neoliberal. Suas narrativas remeteram, de forma recorrente, a produção de uma imagem auto empreendedora da docência, capaz de dar conta por si só das inúmeras demandas geradas com a adoção do ensino remoto. Indício também da incorporação de uma moral de responsabilização.

A emergência dessa nova razão empreendedora assumida pelo indivíduo se sobrepõe ao poder de coerção do Estado, à medida que as tecnologias disciplinares associadas à ordem biopolítica de governo da conduta docente, agem na formação de um sujeito empreendedor de si mesmo. Subjetividade que cultiva um self empreendedor ao tornar-se responsável pelo alcance de metas que passam a ser encaradas como sua responsabilidade, tanto quando os resultados obtidos apontam sucessos, quanto são percebidos como fracassos. Logo: "Essa emergente racionalidade administrativa contemporânea acaba discursando, criando e proporcionando aos indivíduos um poder de "escolha" que passa a alimentar em termos de ganhos uma somatória que supostamente compõem o seu capital humano" (Rosa; Puzio, 2013, p. 219-220).

Assim surge um sujeito cognominado por Foucault (2008) homo ecomonicus induzido a administrar a vida em termos de ganho ou de perda. Tecnologias de governo da conduta em que são administradas ações sob uma racionalidade prática dirigida a determinados objetivos, fazendo com que certas capacidades dos indivíduos sejam exaltadas e outras sejam drasticamente contidas. Governo de condutas e conhecimentos considerados superiores e de maior importância em termos de responsabilidade, disciplina e diligência.

Nesta linha de pensamento, a racionalidade administrativa emergente objetiva transformar a racionalidade prática de realização de tarefas em aproximações que indiquem bem-estar e potencialização de conhecimentos pragmáticos e capacidades individuais. Assim se executa um novo exercício de poder que produz o ideal de subjetividade ativa, economicamente autônoma:

[...] a cultura administrativa passa a operar através de dispositivos psi, de gerenciamento das condutas, que visa não mais disciplinar e oprimir, mas proporcionar ganhos, reconhecimentos e recompensas em saúde mental e qualidade de vida, resultando em um sujeito produtivo e, portanto, um importante capital humano (Rosa; Puzio, 2013, p.224).

Empreendedorismo ancorado numa lógica meritocrática, valorização de determinados competências e habilidades consideradas impreenscindíveis ao exercício da docência, no contexto da pandemia. 
Há que se considerar que a responsabilização pelo êxito do trabalho remoto assumido pelas professoras também reflete a ausência de responsabilidade dos órgãos públicos encarregados de manter a educação, já que os custos iniciais de aquisição de novos equipamentos tecnológicos ficaram por conta delas e a exigência foi de que o ano letivo seria cumprido a qualquer preço. Muitas, precisaram também aprender a utilizá-los, o que demandou ainda mais tempo e trabalho na vida diária destas professoras. Daí ser possível considerar que a sobrecarga de trabalho se somou ao adoecimento físico e emocional, entre outras razões, pela diluição e concomitância do trabalho doméstico e docente nos espaços privados, marcas do empreendedorismo de si que força mulheres professoras - provedoras da família, donas de casa e mães - a dar conta de diversas atividades concomitantemente.

Mas, a maioria das professoras pareceu não atentar para o fato de que a pandemia também afetou suas condições materiais, emocionais e sociais e as dos estudantes, dos demais sujeitos envolvidos no trabalho pedagógico e das comunidades, uma vez que a afirmação de desinteresse, falta de responsabilidade, incapacidade de uso dos artefatos tecnológicos naquilo que julgavam ser a parte que cabia aos outros - estudantes e familiares -, foram as causas indicadas para justificar os resultados ruins e que denotaram para elas o não reconhecimento dos esforços que empregaram para o êxito do trabalho pedagógico via ensino remoto. Elementos que remetem a permanência de uma concepção pedagógica utilitarista, produtivista e meritocrática na qual o/a professor/a ensina e o/a aluno/a aprende, ensinar é transmitir e aprender é receber, repetir o que foi transmitido.

Assim, as falas das professoras indicaram o ajustamento das condutas às demandas produtivistas e utilitaristas intensificadas com o ensino remoto. Por outro lado, apareceu também nas falas de algumas professoras um conjunto de enunciados que sugere percepção das contingências enfrentadas por elas mesma em relação à sobrecarga de trabalho, a ausência de políticas públicas adequadas para dar conta do trabalho, e que caberia ao Estado, o aprofundamento das desigualdades sociais, enfrentado pelos/as estudantes e as famílias. Como foi dito por elas:

"A pandemia revelou de modo claro e nítido as estratificações sociais, assim, em realidades de baixa renda os conteúdos não conseguiram chegar até os alunos na mesma velocidade que nos demais". (professora I)

"Muito confuso! Trabalhamos o triplo de horas que deveríamos, por culpa de um sistema que não se entendeu o ano todo... hora era uma orientação e na hora seguinte havia mudado tudo. Foi um ano muito desafiador e de aprendizado"; "Para a grande maioria não houve aprendizado significativo, os que mais sofreram foram os em vulnerabilidade social, como sempre". (professora J)

"As desigualdades sociais ficaram mais evidentes e os alunos que vivem em vulnerabilidade social tiveram mais dificuldades de acesso às atividades. Mesmo com todo o esforço das escolas, eles tendo o acesso aos materiais impressos, tiveram também dificuldades para resolver as atividades, com pouca ou nenhuma participação dos responsáveis por motivo de trabalho ou baixa escolaridade. Os alunos ficaram prejudicados no processo de aprendizagem neste ano atípico e pandêmico". (professora L) 
Portanto, estas professoras afirmaram, em certa medida, que as condições desiguais de acesso das escolas e dos estudantes aos recursos tecnológicos acarretou prejuízo na aprendizagem. Também questionaram a atribuição de uma culpa ao/a professor/a pelos resultados não alcançados. O sofrimento psíquico, cansaço e frustração aparece também em algumas falas. Assim disseram as professoras:

"Trabalhar em uma escola do Campo não facilita o ensino à distância, os educandos foram prejudicados e depois a culpa do não aprendizado cai sempre nas costas do docente. Por mais esforços que fizemos nesse período em auxiliar e se desdobrar para atender melhor os alunos eu não me senti muito confortável com essa situação. As cobranças eram muitas e injustas, como se nós que não quiséssemos trabalhar presencialmente, e estivéssemos confortavelmente em nossas casas e recebendo por isso. Trabalhamos muito e me senti, acho que também como meus colegas, desvalorizados". (professora E)

"Cansaço devido à dificuldade em lidar com a tecnologia". (professora J)

"As realidades das famílias e o distanciamento é angustiante. Estou cansada. 2020 foi extenuante, amarrado, desamparado pelos governantes, pelo sistema educacional. Não considero que tivemos um ensino à distância, mas atividades remotas, não são a mesma coisa. Sobre os efeitos das atividades remotas senti falta da relação com os alunos, não pela falta do presencial, porque independe dela, mas pela falta de discussão pelos meios interpostos e pela falta de valorização da formação pelos próprios". (professora $\mathrm{M}$ )

Há que se levar em conta que, tanto professoras quanto estudantes e comunidades foram atingidas pela pandemia. Mudanças diárias fizeram parte das suas vidas. Não bastasse a preocupação constante com a ameaça de adoecimento e as mortes causadas pela COVID-19, o desemprego, as dificuldades enfrentadas pela necessidade de sobrevivência, a responsabilidade de fazer valer o ano letivo recaiu sobre as professoras e demais sujeitos envolvidos no processo pedagógico e terem que dar conta por si só das demandas trazidas pela pandemia, é importante destacar que estas professoras não demonstraram uma atitude conformista. Disseram estar dispostas a aprender, a reinventar suas práticas de modo a aproximarem-se mesmo que virtualmente dos estudantes, tornando as aulas mais atrativas, redobrando a atenção ao processo de ensino e aprendizagem. Por isso, algumas frisaram que, ao contrário do que parecia aos olhos de muitas pessoas, não estavam paradas, mas trabalhando intensamente para dar conta dos seus afazeres pedagógicos.

A professora M, em determinado momento durante sua fala, apontou o tempo pandêmico não como falta de capacidades, habilidades, competências instrumentais, mas como deslocamento: "um tempo de abertura, um portal para a criação, tempo potencial para a quebra de modelos e tudo aquilo que está dado em educação, como a aula, por exemplo".

A narrativa dessa professora permite pensar um deslocamento em relação a delimitação pedagógica dos sujeitos aprendentes que só é possível com a desconstrução do corpo modelo disciplinado pela moral auto empreendedora, corpo capturado pelas máquinas do Estado que 
ditam normas de conduta. Outra direção do desejo que desestabilize representações e atos de enunciação atreladas a uma lógica de organização da máquina de captura do capitalismo e neoliberalismo.

\section{Atravessar o espelho}

Para Deleuze e Guattari (2012) tudo é máquina, tudo tem a ver com produção. Máquinas acopladas, engatadas, ligadas a outras de várias formas, sempre em movimento. A máquina de captura do mercado financeirizado, da qualidade empresarial e da lógica neoliberal que regimenta forças para a consolidação de seus interesses esteve em pleno funcionamento no contexto pandêmico. A pesquisa mostrou que o fechamento das escolas afetou vertiginosamente a vida das professoras, dos/as estudantes e das comunidades.

Todo um jogo biopolítico neoliberal foi operado sobre os corpos e os desejos, efetuando a formação de condutas docentes auto empreendedoras, responsabilizadas pelo êxito no cumprimento do ano letivo de 2020. Práticas de governo que prescreveram o lugar de cada um/a no processo produtivo - às professoras cabia adquirir o manejo com as tecnologias para repassar os conteúdos e atividades, aos familiares coube auxiliar e prover os filhos/as das ferramentas ou retirar nas escolas as tarefas e aos estudantes coube acessar as aulas e realizar os deveres escolares. Uma cadeia produtiva que daria o resultado esperado não fosse os desajustes das engrenagens causados pelas mazelas que interrompem o funcionamento da máquina social, gerando cortes nos fluxos produtivos.

Interrupções que indicam os limites de uma operação instrumental do trabalho pedagógico sustentado na transmissão e reprodução mecânica de conhecimentos préestabelecidos, ainda que operados por meio de novas técnicas, novos procedimentos, novos artefatos tecnológicos.

Tornar-se professor/a é sim experimentação que acontece em encontros de linhas de forças que se afetam mutuamente e movem o pensamento a pensar e aprender diferentemente. Para Deleuze (2003), o aprendizado tem a ver com signos, tudo que nos ensina algo emite signos que se entrecruzam e constituem de diversos modos:

Os signos são objeto de um aprendizado temporal, não de um saber abstrato. Aprender é, de início, considerar uma matéria, um objeto, um ser, como se emitissem signos a serem decifrados, interpretados. Não existe aprendiz que não seja "egiptólogo" de alguma coisa. Alguém só se torna marceneiro tornando-se sensível aos signos da madeira, e médico tornando-se sensível aos signos da doença. (Deleuze, 2003, p.4)

Aprender é tornar-se outro, expansão de potências, criação de linhas de forças e fugas de uma máquina de guerra que possibilita experimentar devires-outros:

[...] um acontecimento ou, dito de outro modo, o passar de algo que não sou eu. E "algo que não sou eu" significa também algo que não depende de mim, que não é 
uma projeção de mim mesmo, que não é resultado de minhas palavras, nem de minhas ideias, nem de minhas representações, nem de meus sentimentos, nem de meus projetos, nem de minhas intenções, que não depende nem do meu saber, nem de meu poder, nem de minha vontade. "Que não sou eu" significa que é "outra coisa que eu", outra coisa do que aquilo que eu digo, do que aquilo que eu sei, do que aquilo que eu sinto, do que aquilo que eu penso, do que eu antecipo, do que eu posso, do que eu quero (Larrosa, 2011, p. 05).

Ou seja, o que se diz ser "eu” docente, o que pode ser "eu”, é sempre uma totalidade abstrata inalcançável, como uma imagem no espelho. Não somos docentes, nos tornamos docentes, criamos estilos de um ato inventado no fazer docente, um fazer por fazer-se e que acontece na convivência e interação entre pares e com os/as estudantes, com ou sem o uso de artefatos tecnológicos e digitais. Não são as metodologias que definem o trabalho pedagógico por si só. Elas são ferramentas, não mais que isso.

E, se até Narciso foi corajoso ao ponto de se afogar nas águas em busca de encontrar o outro que tanto amava, por que não encarar o espelho? Arriscar-se a duvidar do que se pensa e se diz o verdadeiro docente? Como disse uma das professoras entrevistadas, por que não "enfrentar o caos"?

\section{Notas:}

1. A expressão "beleza narcísica" é usada aqui como um aforismo que remete ao Mito de Narciso, personagem da mitologia grega que amava o reflexo da própria imagem, relacionando-a à ideia de uma docência que é produzida como reflexo do governo da conduta docente, projetada e admirada pelos/as professores/as que perseguem a eficiência e acreditam que o sucesso depende do seu próprio esforço e da capacidade de adaptar-se às exigências das tecnologias de instrumentalização do trabalho pedagógico via ensino remoto.

2. O coronavírus é uma espécie de vírus que causa infecção respiratória aguda e pode levar a morte. Desde 2010, essa doença assola o mundo inteiro, daí porque foi decretada a pandemia do COVID-19 pela Organização Mundial da Saúde e indicadas medidas de isolamento social para contenção da doença. Os primeiros casos foram diagnosticados na cidade de Wuhan, na longínqua China, a doença tomou força na Itália, espalhou-se pela Europa e nos demais continentes, afetando todos os países e acarretando inúmeras mortes. Os dados publicados em janeiro de 2021 pela Universidade de Johns Hopkins (Estados Unidos), mostram que já passava de dois milhões de óbitos em todo mundo, sendo que, os Estados Unidos e o Brasil lideram, desde então, essas estatísticas de morte (Disponível em: https://agenciabrasil.ebc.com.br Acesso em: 12/07/200).

3. Segundo o Boletim Epidemiológico editado pelo Ministério da Saúde, em 10 de abril de 2021, o Brasil alcançou o patamar de 351 mil mortes, número menor apenas que os EUA, o que evidencia a debilidade das políticas sanitárias adotadas para contenção da doença. (Disponível em: https://www.gov.br/saude/ptbr/media/pdf/2021/abril/16/boletim_epidemiologico_covid_581.pdf Acesso em: 12/07/200). 


\section{Referências}

DELEUZE, Gilles. Proust e os signos. $2^{\mathrm{a}}$ ed. Tradução de Antônio Piquet e Roberto Machado. Rio de Janeiro. Forense Universitária, 2003.

DELEUZE, Gilles; GUATTARI, Félix. Mil Platôs: capitalismo e esquizofrenia 2, v. 01. Tradução de Aurélio Guerra Neto e Célia Pinto Costa, São Paulo. Editora 34, 2012.

FISCHER, Rosa Maria Bueno Foucault e a análise do discurso em educação. Caderno de Pesquisa, n.114, nov. 2001, p.197-223.

FOUCAULT, Michel. Arqueologia do Saber. $7^{\text {a }}$ edição. Tradução: Luiz Felipe Baeta Neves, Rio de Janeiro, Editora Forense Universitária, 2005.

FOUCAULT, Michel. Nascimento da Biopolítica. $1^{a}$ ed. Tradução de Eduardo Brandão. São Paulo. Coleção Tópicos, 2008.

HARDT, Michael; NEGRI, Antonio. Império. 10a ed. Tradução de Herilo Vargas. Rio de Janeiro/São Paulo: Editora Record, 2012.

LARROSA, Jorge. Experiência e Alteridade em Educação. Revista Reflexão e Ação. Santa Cruz do Sul, v.19, n. 2, jul./dez. 2011.

ROLNIK, Suely. Esferas da Insurreição: notas para uma vida não cafetinada. $2^{a}$ ed. São Paulo: n-1 edições, 2018.

ROSA, Pablo O. PUZIO, Marcelo. Governamentalizando o empreendedorismo de si: como as "psico-ciências" fomentam a produção do homo economicus. Revista Sociologias Plurais. Curitiba, v.1, n.2, 2013, p.216229.

\section{Correspondência}

Dulce Mari Silva Voss: É Doutora em Educação. Professora Associada da Universidade Federal do Pampa. Líder do Grupo de Pesquisa Philos Sophias.

E-mail: dulcevoss@unipampa.edu.br

Texto publicado em Currículo sem Fronteiras com autorização dos autores. 